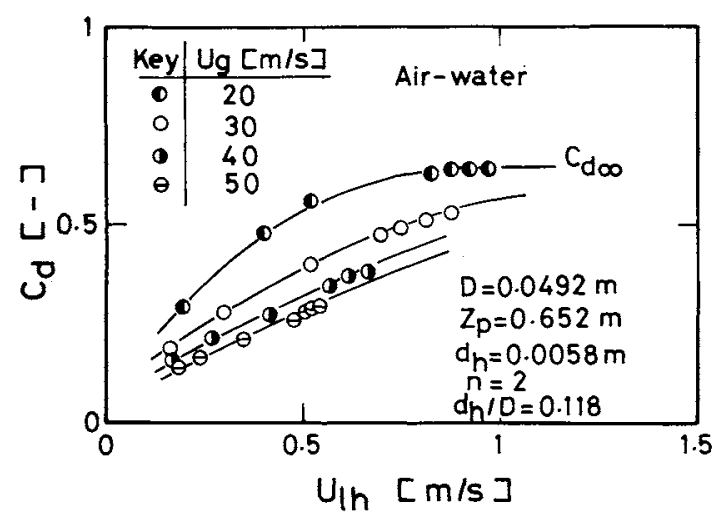

Fig. 5. Discharge coefficient.

$U_{l} \quad=$ superficial liquid velocity based on empty pipe

$U_{l h} \quad=$ liquid velocity through holes

$Z \quad=$ distance

$Z_{D} \quad=$ measuring position for pressure in pipe

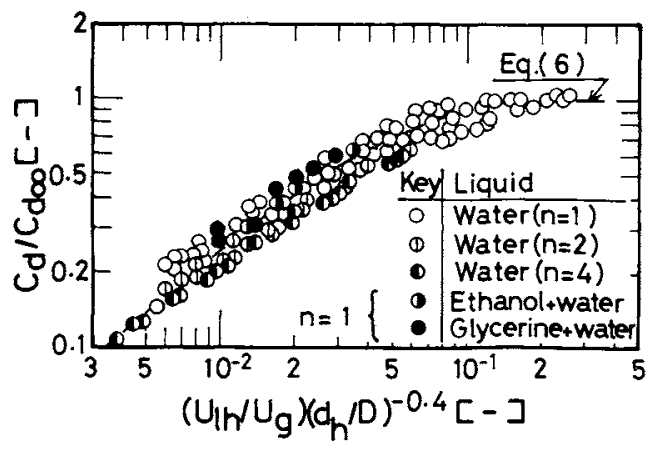

Fig. 6. Correlation of discharge coefficient.

$\begin{array}{ll}\theta & =\text { angle } \\ \varphi & =\text { liquid holdup }\end{array}$

[rad]

Literature Cited

1) Takahashi, T., T. Miyahara, T. Sato and Y. Sanada: J. Chem. Eng. Japan, 19, 456 (1986).

\title{
ON THE PERMEATION MECHANISM OF ULTRAFILTRATION WITH AN ANODIC ALUMINUM OXIDE MEMBRANE
}

\author{
SHIzUo SUGAWARA, IKUO SAKURAI, Mikio KONNO AND SHOZABURo SAITO \\ Department of Chemical Engineering, Tohoku University, Sendai 980
}

\begin{abstract}
Key Words: Ultrafiltration, Pore Model, Permeation Mechanism, Aluminum Oxide Membrane, Inorganic Membrane
\end{abstract}

\section{Introduction}

The pore model originally proposed by Ferry ${ }^{33}$ for the mechanism of ultrafiltration has been developed by a number of investigators. ${ }^{8,9,12)}$ However, the validity of the model has not been sufficiently examined since most investigators in past experimental work employed polymer membranes with complex pore structures.

Recently, the authors reported a preparation method for an inorganic membrane, porous anodic aluminum oxide film ${ }^{4)}$ which had a well-defined pore structure in terms of the straightness of the pores and the narrow distribution in pore size. The present work is aimed at examining the validity of the pore theory using this membrane.

\section{Experimental}

To improve the poor resistance of the aluminum

\footnotetext{
Received April 18, 1986. Correspondence concerning this article should be addressed
} to $\mathrm{S}$. Saito. oxide membrane to water, ${ }^{11}$ the surface of the membrane was chemically modified by a condensation reaction* prior to experiments. Figure 1 shows the efficiency of the surface modification observed in the preliminary experiments of water permeation. The reduction in permeation rate that occurred with the unmodified membrane scarcely appeared with the modified one.

Experiments were conducted in a permeation cell equipped with a stirrer at its center. A modified membrane was located at the bottom of the cell. Figure 2 presents the dimensions of the cell. In each run, dilute aqueous solutions were used. The solutes used were monodispersed polyethylene glycol (PEG) of three different molecular weights, bovine serum hemoglobin and bovin serum $\gamma$-globulin. The concentration of the aqueous solutions was adjusted to

\footnotetext{
* Stearic acid was used as condensation agent, and dicyclohexylcarbodiimide as a condensation catalyst. Stearic acid reacts with hydroxyl groups existing on the surface of aluminum oxide substances in the presence of the catalyst. ${ }^{7)}$
} 


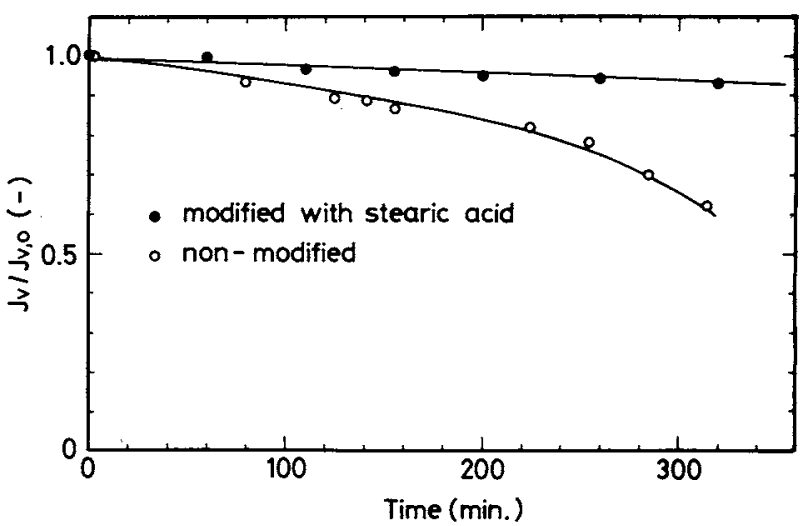

Fig. 1. Experimental results for permeation rate of modified and unmodified aluminum oxide membranes.

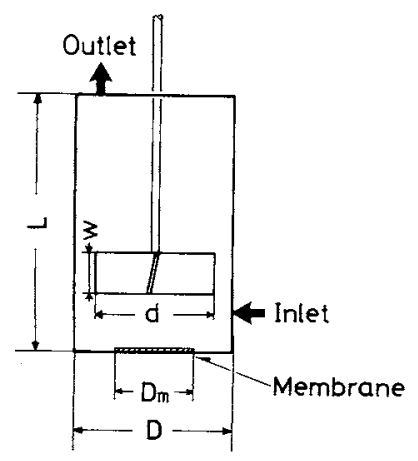

$D=40 \mathrm{~mm}$

$D_{m}=20 \mathrm{~mm}$

$\mathrm{L}=94 \mathrm{~mm}$

$\mathrm{d}=35 \mathrm{~mm}$

$w=12 \mathrm{~mm}$

Fig. 2. Dimensions of permeation cell.

$0.1 \mathrm{wt} \%$ in all experiments. The concentrations of the permeate solutions were measured at different stirring speeds and pressures in the cell.

The properties of the membranes and the solutes are presented in Tables $\mathbf{1}$ and $\mathbf{2}$. As shown in Table 1, two modified membranes of different pore sizes were prepared for the present experiments. The pore sizes of the membranes, ${ }^{*} r_{p}$, were determined by the gas permeation method ${ }^{4}$ previously reported. The values of the molecular radius in Table 2 were determined from the diffusion coefficients ${ }^{1)}$ with the following Stokes-Einstein equation:

$$
r_{\mathrm{s}}=k T /\left(6 \pi \mu D_{\mathrm{s}}\right)
$$

where $D_{\mathrm{s}}$ is a diffusion coefficient, $k$ Bolzmann's constant, and $\mu$ the viscosity of the solution.

\section{Results and Discussion}

\subsection{Pore theory}

In pore theory, ${ }^{2.9,12)}$ a number of assumptions have

* The pore sizes determined by the gas permeation method were consistent with the values determined from water permeation rate with the Hagen-Poiseuille equation.
Table 1. Properties of modified membranes

\begin{tabular}{|c|c|c|c|}
\hline & & Membrane 1 & Membrane 2 \\
\hline & {$[\mathrm{nm}]$} & 8.8 & 5.0 \\
\hline$l^{\mathrm{p}}$ & {$[\mu \mathrm{m}]$} & 67 & 50 \\
\hline & {$\left[\mathrm{cm}^{-2}\right]$} & \multicolumn{2}{|c|}{$4.6 \times 10^{10}$} \\
\hline & {$[-]$} & 0.112 & 0.036 \\
\hline
\end{tabular}

* For pore size determination, nitrogen gas was used at a temperature of $290 \mathrm{~K}$ in a pressure range of 100 to $800 \mathrm{mmHg}$.

Table 2. Properties of solutes (at $20^{\circ} \mathrm{C}$ )

\begin{tabular}{lccc}
\hline Solute & Molecular weight & $\begin{array}{c}D_{\mathrm{s}} \times 10^{7 *} \\
{\left[\mathrm{~cm}^{2} / \mathrm{s}\right]}\end{array}$ & $\begin{array}{c}r_{\mathrm{s}} \\
{[\mathrm{nm}]}\end{array}$ \\
\hline PEG 7500 & 7500 & 8.46 & 2.54 \\
PEG 18000 & 18000 & 5.07 & 4.24 \\
PEG 39000 & 39000 & 3.22 & 6.67 \\
Hemoglobin & 64000 & 6.30 & 3.41 \\
Y-Globulin & 150000 & 4.40 & 4.88 \\
\hline
\end{tabular}

* Cited from the literature. ${ }^{1)}$

been made: 1) the molecules of a solute have a rigid and spherical shape; 2) a membrane has straight, cylindrical pores, of uniform diameter, which are perpendicular to the membrane surface; 3) solute transfer in the membrane consists of filtration and diffusion flows; and 4) the molecular force between pore wall and solute or solvent can be ignored.

On the basis of these assumptions, hydrodynamic equations of motion were solved and their analytical results were used to determine membrane rejection defined by the following equation:

$$
R_{\mathrm{t}}=\left(C_{\mathrm{m}}-C_{\mathrm{p}}\right) / C_{\mathrm{m}}
$$

where $C_{\mathrm{m}}$ is the solute concentration in feed on the surface of the membrane, and $C_{\mathrm{p}}$ the concentration of the permeate solution. According to previous workers, ${ }^{8,10,12)}$ whose results were reviewed by Nakao and Kimura, ${ }^{6}$ an approximate analytical solution for membrane rejection is expressed as follows:

$$
R_{\mathrm{t}}=\sigma(1-F) /(1-\sigma F)
$$

where

$$
F=\exp \left\{-J_{\mathrm{v}}(1-\sigma) / P_{\mathrm{s}}\right\}
$$

In these equations, $J_{v}$ is the volume flux, $\sigma$ the reflection coefficient, and $P_{s}$ the solute permeability. The functional forms of $\sigma$ and $P_{\mathrm{s}}$ are given by

$$
\begin{gathered}
\sigma=1-g(q)\left\{2(1-q)^{2}-(1-q)^{4}\right\} \\
P_{\mathrm{s}}=D_{\mathrm{s}} f(q)(1-q)^{2} A_{\mathbf{k}} / l
\end{gathered}
$$

where

$$
q=r_{s} / r_{p}
$$




$$
\begin{gathered}
f(g)=\left(1-2.1 q+2.1 q^{3}-1.7 q^{5}+0.73 q^{6}\right) / \\
\left(1-0.76 q^{5}\right) \\
g(q)=\left(1-0.67 q^{2}-0.2 q^{5}\right) /\left(1-0.76 q^{5}\right)
\end{gathered}
$$

And $A_{\mathrm{k}}$ is the ratio of total cross-sectional pore area to effective membrane area and $l$ the pore length. The parameters of the model are $D_{\mathrm{s}}, A_{\mathrm{k}}, l, r_{\mathrm{s}}$ and $r_{\mathrm{p}}$, the values of which are listed in Tables 1 and 2 .

\subsection{Comparison of theoretical and experimental re- sults}

Under the experimental conditions, the volume flux of permeate solution ranged from $4.43 \times 10^{-5}$ to $1.59 \times 10^{-3}\left(\mathrm{~cm}^{3} / \mathrm{cm}^{2} \cdot \mathrm{s}\right)$. With values of the flux in this range, calculation of the rejection $R_{\mathrm{t}}$ from Eq. (3) showed that the term $F$, which includes the effect of diffusion, can be neglected in comparison with $\sigma$. Therefore, the theoretical value of $R_{\mathrm{t}}$ is dependent only on the radius ratio $r_{\mathrm{s}} / r_{\mathrm{p}}$ and is thus independent of the pressure difference $\Delta P$ and the stirring speed $n_{\mathrm{r}}$.

Owing to concentration polarization on the membrane surface, the value of $R_{\mathrm{t}}$ is usually different from the experimentally obtained rejection, $R_{\mathrm{obs}}$, which is defined by the following equation:

$$
R_{\text {obs }}=\left(C_{\mathrm{b}}-C_{\mathrm{p}}\right) / C_{\mathrm{b}}
$$

where $C_{\mathrm{b}}$ is the bulk concentration of feed. The value of $R_{\mathrm{t}}$ will probably be consistent with that of $R_{\text {obs }}$ only when $n_{\mathrm{r}}$ is sufficiently high and $\Delta P$ is sufficiently low.

Figure 3 shows the experimental results of $R_{\mathrm{obs}}$ for the membrane with $r_{\mathrm{p}}=8.8 \mathrm{~nm}$ using the solute of PEG $\left(M_{w}=7,500\right)$. In the figure, the experimental data reveal the dependence of $R_{\text {obs }}$ on $n_{\mathrm{r}}$ and $\Delta P$. Thus the effect of concentration polarization on rejection was not eliminated under the present experimental conditions. It is clear, then, that concentration polarization must be considered to obtain $R_{\mathrm{t}}$ values from the experimental results.

According to the concentration polarization model proposed by Kimura and Sourirajan, ${ }^{5)}$ the bulk concentration $C_{\mathrm{b}}$ is related to the surface concentration $C_{\mathrm{m}}$ as follows:

$$
J_{\mathrm{v}}=k \cdot \ln \left\{\left(C_{\mathrm{m}}-C_{\mathrm{p}}\right) /\left(C_{\mathrm{f}}-C_{\mathrm{p}}\right)\right\}
$$

where $k$ is the mass transfer coefficient in the boundary layer on the membrane. The value of $k$ is a function of the impeller Reynolds number and can be given as

$$
k \propto n_{\mathrm{r}}^{\mathrm{a}}
$$

In addition, the experimental results indicated the direct proportionality of $J_{\mathrm{v}}$ to $\Delta P$. Using this relation and Eq. (12), the following equation is obtained from Eq. (11):

$$
\ln \left\{\left(1-R_{\mathrm{t}}\right) / R_{\mathrm{t}}\right\}=\ln \left\{\left(1-R_{\text {obs }}\right) / R_{\text {obs }}\right\}-\left(b / n_{\mathrm{r}}^{\mathrm{a}}\right) \cdot \Delta P
$$

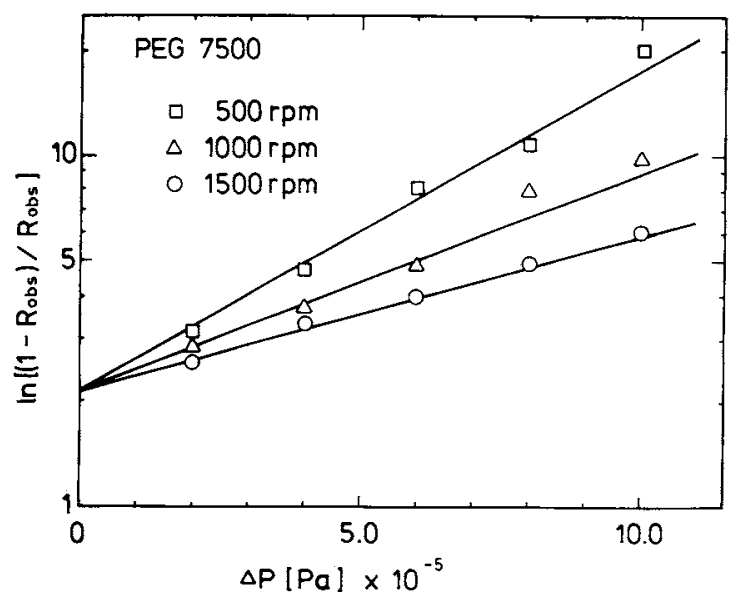

Fig. 3. Experimental results of $R_{\mathrm{obs}}$ for membrane with $r_{p}=$ $8.8 \mathrm{~nm}$ using solute of PEG 7500.

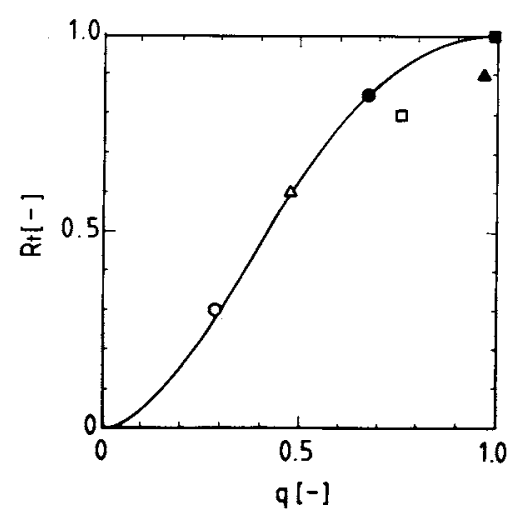

Fig. 4. Comparison of theoretical and experimental results of rejection. Exp. for $r_{p}=8.8 \mathrm{~nm}$ : (O) PEG 7500; $\triangle$ ( $\mathrm{PEG}$ 18000; ( $\square$ ) PEG 39000. Exp. for $r_{p}=5.0 \mathrm{~nm}$ : (O) hemoglobin; (A) PEG 18000; (囬) globulin.

where $a$ and $b$ are constants.

This equation indicates that the values of $R_{\mathrm{obs}}$ converge to the $R_{\mathrm{t}}$ value with decreasing $\Delta P$. According to Eq. (13), the experimental values of $R_{\text {obs }}$ for different impeller speeds are plotted in Fig. 3. The values of $R_{\mathrm{obs}}$ at each impeller speed are found to converge to a certain value when $\Delta P$ becomes zero, as expected from Eq. (13). Therefore, this kind of interpolation method was applied in this work to determine $R_{t}$ values from the experimental values of $R_{\text {obs. }}$.

In Fig. 4, all the data of $R_{\mathrm{t}}$ obtained experimentally are compared with theoretical values from Eq. (3). Pore theory is found to be useful for prediction of values close to the experimental ones, although the experimental data for both PEG $\left(M_{w}=39,000\right)$ with $r_{\mathrm{p}}=8.8 \mathrm{~nm}$ and PEG $\left(M_{w}=18,000\right)$ with $r_{\mathrm{p}}=5.0 \mathrm{~nm}$ are somewhat different from the theoretical values. These discrepancies may be due to the inadequacy of the assumption of molecule rigidity, since chain polymers such as polyethylene glycol are apt to be distorted easily owing to shear stress in membrane pores, especially when molecular-to-pore radius ratio 
$q$ is relatively large.

\section{Nomenclature}

$A_{\mathrm{k}} \quad=$ ratio of total cross-sectional pore area to effective area

a $\quad=$ constant

$b \quad=$ constant

$C_{\mathrm{b}} \quad=$ bulk concentration in feed

$C_{\mathrm{m}} \quad=$ concentration in feed on the surface of membrane

$C_{\mathrm{p}} \quad=$ concentration of permeate solution

$D_{\mathrm{s}} \quad=$ diffusion coefficient of solute

$J_{\mathrm{k}} \quad=$ mole fiux of Knudsen diffusion

$J_{\mathrm{v}} \quad=$ volume flux

$k \quad=$ Boltzmann's constant

$l \quad=$ pore length

$M \quad=$ molecular weight

$N \quad=$ pore density

$n_{\mathrm{r}} \quad=$ stirring speed

$P_{\mathrm{s}} \quad=$ solute permeability

$\triangle P \quad=$ pressure difference

$q \quad=r_{\mathrm{s}} / r_{\mathrm{p}}$

$R \quad=$ gas constant

$R_{\text {obs }} \quad=$ observed rejection

$R_{\mathrm{t}} \quad=$ rejection $r_{\mathrm{p}} \quad=$ pore radius

[cm]

$r_{\mathrm{s}} \quad=$ solute radius

[cm]

$\sigma \quad=$ reflection coefficient

$[-]$

$\mu \quad=$ viscosity

$[\mathrm{kg} / \mathrm{cm} \cdot \mathrm{s}]$

$[-]$

$[-]$

Literature Cited

$\left[\mathrm{mol} / \mathrm{cm}^{3}\right]$

$\left[\mathrm{mol} / \mathrm{cm}^{3}\right]$

$\left[\mathrm{mol} / \mathrm{cm}^{3}\right]$

$\left[\mathrm{cm}^{2} / \mathrm{s}\right]$

$\left[\mathrm{mol} / \mathrm{cm}^{2} \cdot \mathrm{s}\right]$

$\left[\mathrm{cm}^{3} / \mathrm{cm}^{2} \cdot \mathrm{s}\right]$

$[\mathrm{J} / \mathrm{K}]$

[cm]

$[\mathrm{g} / \mathrm{mol}]$

$\left[\mathrm{cm}^{-2}\right]$

$\left[\mathrm{s}^{-1}\right]$

$[\mathrm{cm} / \mathrm{s}]$

[Pa]

$[-]$

$[\mathrm{J} / \mathrm{mol} \cdot \mathrm{K}]$

[-]
1) Brandrup, J. and E. G. Immergut (ed.): "Polymer Handbook," Interscience, New York (1966).

2) Durbin, R. P.: J. Gen. Physiol., 44, 315 (1960).

3) Ferry, J. D.: Chem. Rev., 18, 373 (1936).

4) Itaya, K., S. Sugawara, K. Arai and S. Saito: J. Chem. Eng. Japan, 17, 514 (1984).

5) Kimura, S. and S. Sourirajan: $A I C h E J ., 13,497$ (1967).

6) Nakao, S. and S. Kimura: J. Chem. Eng. Japan, 14, 32 (1981).

7) Osa, T. and M. Fujihira: Membrane, 6, 321 (1981).

8) Pappenheimer, J. R., E. M. Renkin and L. M. Borrero: Am. J. Physiol., 167, 13 (1951).

9) Renkin, E. M.: J. Gen. Physiol., 38, 225 (1954).

10) Spiegler, K. S. and O. Kedem: Desalination, 1, 311 (1966).

11) Wood, G. C. and J. P. O'Sullivan: J. Electrochem. Soc., 116, 1351 (1969).

12) Verniory, A., R. Du Bois, P. Decoodt, J. P. Gassee and P. P. Lambert: J. Gen. Physiol., 62, 489 (1973). 